\title{
La enseñanza del cine en la Educación Superior: El caso de la Facultad de Bellas Artes de Cuenca
}

\author{
Teaching Cinema in Higher Education: the case of the Faculty of \\ Fine Arts of Cuenca
}

Ignacio Oliva Mompeán

\begin{abstract}
"Vivimos en el mundo del triunfo de la imagen, za dónde fueron a parar las sensaciones?" Con estas palabras, la directora belga Chantal Akerman mostraba que, a pesar de ser una de las más grandes y reconocidas figuras del cine europeo, no era muy feliz en este mundo inundado de imágenes. Todos miramos imágenes continuamente, en especial, los más jóvenes. Sólo hay que echar un vistazo a la calle, al transporte público, a cualquier espacio social. Estamos dominados por la imagen. Y todo empezó con la irrupción del cine, que supuso un cambio profundo en el pensamiento y una transformación radical de nuestra manera de mirar. También dio un nuevo contenido al espacio de la representación visual, en tanto que un fenómeno de la imaginación, de tal modo que se podría decir que nunca fuimos los mismos desde su aparición. Sin embargo, este dominio hegemónico de la imagen, en la que el cine tiene una presencia muy relevante hoy no se corresponde con un estadio formativo en torno a su fundamentación en los distintos niveles educativos. Esta es la razón por la que se ha puesto en marcha un amplio debate centrado en la importancia de introducir la enseñanza del cine y la cultura visual en los distintos programas de estudios. Han sido muchos los informes especializados que recientemente han señalado la necesidad de una llamada "alfabetización audiovisual" que sensibilice y forme a los espectadores, especialmente a los más jóvenes. Como Akerman, otro relevante cineasta, José Luis Guerín, fue preguntado por una película que él pensara que debiera ser obligatoria en los colegios: "Sin estar nada seguro de la pertinencia de obligar, podría ser interesante proyectarles ¿Dónde está la casa de mi amigo?, de Kiarostami"' . La recomendación es muy adecuada e incide en el acuerdo generalizado sobre la necesidad de introducir la enseñanza del cine y de la comunicación audiovisual en el sistema educativo, debate que ha avanzado significativamente en los últimos años. En este sentido, una referencia específica interesante es la revista Cinema Comparative Cinema en su número 5. En el editorial del volumen II, Gonzalo de Lucas expone su preocupación por diversos modelos formativos respecto al cine, en cuanto a "experiencias y metodologías de la transmisión del ver y del filmar, evitando los riesgos del academicismo y haciendo del cine una historia viva y vívida" (de Lucas, 2014). El cine cumple hoy una función educativa importante como apoyo para abordar ciertos temas curriculares. Todos los colegios e
\end{abstract}

\footnotetext{
${ }^{1}$ El director iraní Abbas Kiarostami, recientemente desaparecido, es uno de los directores más importantes del cine reciente y en su última época estuvo muy implicado en la enseñanza, con el desarrollo de talleres formativos.
} 
institutos incluyen un número relevante de visionados de películas como complemento formativo, pero se trata de ir más allá del puro carácter ilustrativo y avanzar hacia una profundización en el medio. El cine es el arte más influyente de nuestro tiempo y es preciso conocerlo, comprenderlo y valorarlo adecuadamente. Si es un hecho que hoy se consume más cine que nunca, por el enorme desarrollo de contenidos digitales presentes en los dispositivos móviles que forman parte (casi) indisoluble de nuestras vidas, parece dramático que la mayoría de los jóvenes universitarios españoles de veinte años sepan quiénes son, por poner un ejemplo, "Los Javis" y no quién es Pasolini. Es cierto que la Institución Cine, por su parte, ha reaccionado en los últimos años con la inclusión de espacios formativos dirigidos a los espectadores más jóvenes en la mayoría de festivales, espacios diseñados expresamente para establecer una sensibilización con los elementos fundamentales del cine, pero, del mismo modo que es preciso que los estudiantes de secundaria sepan quiénes son Shakespeare, Picasso o Mozart, también es preciso que sepan quiénes son Murnau, Ford o Rossellini, un cineasta que, por cierto, tanto se preocupó por establecer una pedagogía educativa². La pertinencia de un estadio formativo básico sobre el arte cinematográfico en la enseñanza secundaria parece trascendental, no sólo para contribuir a que los estudiantes tengan un mayor background cultural sino, sobre todo, para crear en ellos a un espectador crítico. Esta formación debe estar presente en un programa de estudios ambicioso, diverso, ordenado y diseñado de un modo específico, para que evite visiones sesgadas. Pero el objetivo de estas páginas es abordar este debate en el espacio formativo de la Educación Superior y, particularmente, en la experiencia de la Facultad de Bellas Artes de Cuenca, a lo largo de tres décadas, entre 1990 y 2020. Pasamos, seguidamente, a situar algunas reflexiones al respecto.

\section{Una breve perspectiva personal}

Llevo más de treinta años enseñando cine en la universidad y mi experiencia docente puede ofrecer una perspectiva interesante sobre uno de los centros donde la enseñanza del cine se ha llevado a cabo de un modo pionero y con especial amplitud y profundidad, como es la Facultad de Bellas Artes de Cuenca. A modo introductorio, ofreceré unas breves pinceladas sobre mi formación inicial en la Facultad de Bellas Artes de Valencia, entre 1980 y 1985. Fue un tiempo de grandes cambios. Eran los momentos finales de la llamada Transición política. Aquella nueva Facultad provenía del modelo tradicional de una antigua Escuela Superior. Aún había en ella un fuerte contenido académico y algunas paradojas históricas, como un decano que había sido requeté. Fueron años de una gran agitación, que tuvo una prueba de fuego en el intento de golpe militar, al que asistí en una ciudad sitiada por un general exaltado. Pocos meses después, tuve la suerte de asistir a la última conferencia del legendario pintor y cartelista republicano Josep Renau. Eran tiempos con esos contrastes. En aquellos primeros años de formación artística he de señalar el magisterio que ejerció sobre mí el historiador y crítico del cine Juan Miguel Company, a principios de los 80. Él era ya una figura referencial en la teoría e historia del cine en España y reorientó mis últimos años de carrera, en los que comencé a hacer películas en formato Super 8. También me ayudó en la composición de mi Memoria de Licenciatura, que se centró en un estudio sobre el espacio visual en El gabinete del Doctor Caligari (Das Cabinet des Dr. Caligari, Robert Wiene, 1920). Pocos años después de esta iluminadora experiencia formativa, fui invitado a incorporarme como profesor en la Facultad de Bellas Artes de Cuenca, creada en 1984 y que entonces dirigía el crítico de arte José Luis Brea. La Facultad tenía un planteamiento muy abierto y allí tuve la posibilidad de introducir los estudios de cine. En los primeros años, hasta mediados de los noventa, diseñamos un planteamiento centrado en disciplinas teóricas como historia, sociología

\footnotetext{
${ }^{2}$ A este respecto es interesante el documental La última utopía (La dernière utopie: La télévision selon Rossellini, 2006) del teórico y documentalista Jean-Louis Comolli, en el que investiga sobre el último proyecto de Roberto Rossellini, en el que el director italiano quería filmar una historia de la humanidad a través de una televisión educativa, comprometida y transformadora.
} 
y psicología del cine, pero a partir de 1995 abrimos las posibilidades formativas hacia orientaciones más ligadas hacia un diálogo entre la teoría y la práctica. La primera asignatura que introdujimos en esta nueva orientación fue Teoría y Práctica del cine y durante esos años trabajamos de un modo experimental en la realización de prácticas tutoradas y semiprofesionales. La propia deriva de la cultura visual, en la que el cine y las artes audiovisuales fueron adquiriendo una relevancia cada vez mayor, nos impulsó a ampliar estos estudios y en los planes sucesivos fuimos consolidando itinerarios más específicos, con un mayor número de asignaturas centradas en los medios audiovisuales. Podríamos decir que en los últimos veinticinco años hemos pasado de una implantación inicial de asignaturas de corte teórico, cimentadas en clases magistrales, a un conjunto de talleres en los que la teoría cumple una función de fundamentación conceptual y ejercicio crítico para el desarrollo de casos prácticos. En los planes de estudio más recientes, hemos incluido asignaturas optativas como Taller de cinematografía, Dirección de Arte, iluminación y espacio o Postproducción, en los estudios de Grado, y Práctica cinematográfica en los estudios de Máster. Con estas asignaturas pretendemos perfilar una formación lo más completa posible, atendiendo a la introducción de las distintas orientaciones profesionales del cine. Pero toda nuestra experiencia de capacitación cinematográfica se ha desarrollado con estudiantes que llegaban con una muy escasa o casi nula formación previa en el terreno cinematográfico, por eso nos parece muy necesario que los estudiantes de cine futuros accedan a la Enseñanza Superior con una mejor formación previa.

\section{Una constatación inicial}

He señalado que el cine es el arte más influyente de nuestro tiempo y esta afirmación no pretende erigir órdenes de importancia en la formación artística, sino señalar criterios como la repercusión social o la inversión económica que mueven las industrias audiovisuales en todo el mundo, fenómenos de una magnitud incomparablemente mayor en el cine que en ningún otro fenómeno artístico contemporáneo. Esta presencia central del cine y las llamadas artes audiovisuales en nuestras vidas justifica que su estudio deba tener ese recorrido transversal que hemos señalado en los distintos estados formativos, pero es preciso hacer una constatación sobre el fenómeno cinematográfico contemporáneo, porque no hay un cine, sino muchos cines. En tanto que fenómeno artístico dotado de una marcada carga aurática ${ }^{3}$, el cine parece escorarse hoy hacia los territorios cada vez más indefinidos, en un mundo en que el propio soporte audiovisual y el desarrollo tecnológico han abierto considerablemente sus posibilidades expresivas, no sólo en el territorio de la producción sino también, y especialmente, en el de la exhibición. Aunque al cine se le ha dado por muerto muchas veces (Lenne, 1974) ${ }^{4}$ y aún se sigue hablando de ello, sobre todo, en determinados círculos de la llamada cinefilia, se calcula que en 2025 se rodarán alrededor de 100.000 millones de horas de cine en todo el mundo, una cifra vertiginosa. Hoy se produce y se consume más cine que nunca. El número de festivales resulta igualmente inabarcable. Lo que parece claro, al margen de esencialismos, es que el arte cinematográfico se transforma, inevitablemente, por las imposiciones del avance tecnológico y por las complejas variables sociales del mundo

\footnotetext{
${ }^{3}$ A este respecto resulta iluminador el interesante ensayo de Miriam Bratu Hansen: Cinema and Experience. Siegfried Kracauer, Walter Benjamin and Theodor W. Adorno (Bratu Hansen, 2012).

${ }^{4}$ También se habla de la muerte del cine en el Manifiesto de Oberhausen o en el documental Histoire(s) du Cinéma, de Jean Luc Godard (1988-1998), entre otros muchos espacios. Adrian Martin, uno de los más lúcidos historiadores y críticos del cine actuales, afirma: "Soñemos por un momento. Soñemos que las películas-tanques han muerto y se han ido; que Hollywood y todos sus imitadores ya se han derrumbado. Soñemos que sólo quedamos ustedes y yo, involucrados en el frágil gesto del arte correo cinematográfico. Lo filmamos con nuestros teléfonos, lo editamos en nuestras laptops y lo enviamos a otras pantallas domésticas. Este es el cine hoy. Todo lo que queda del cine. O, más bien, es todo lo que hay de cine. Todo el cine, despojado hasta su núcleo esencial. Lo que el cine debió haber sido siempre" (Martin, 2020: 143).
} 
globalizado. Tal vez sería más productivo preguntarse por fenómenos como la progresiva sustitución de la realidad física por la virtual, con el desarrollo de herramientas y programas de efectos especiales, o la propia sustitución de la presencia física del actor, que en pocos años pasará a ser una replica digital acaso más real, más humana, que la propia condición física. Estos fenómenos replantean de un modo radical, entre otras cosas, la condición ontológica del cine propuesta por Bazin (1990) $)^{5}$. El viejo cine afronta su propio has been para redefinir su still been en el marco de la cultura contemporánea, a la que aportó algo tan importante como la creación de un público nuevo para este nuevo arte. Si lo que define a cualquier fenómeno cultural es su tradición, es decir, su presencia y continuidad en el proceso histórico, el cine tiene hoy grandes exigencias que resolver en el amplio y complejo contexto de la cultura visual en el que está integrado, donde los debates estéticos en torno a las distintas hibridaciones contemporáneas de la imagen visual se unen a las posibilidades de su presencia social y de consumo. Este es otro debate, que excede sin duda el objeto de estas páginas, pero la severa transformación que está ocurriendo en la producción y la exhibición tiene una inevitable correspondencia con los movimientos de concentración empresarial y de absorción de compañías que se está produciendo en toda Europa, y también en España. Aún es pronto para ver con claridad y analizar cuáles y de qué calado van a ser las transformaciones y consecuencias que se están produciendo en el entono de la creación y comercialización cinematográfica y audiovisual contemporánea, pero la industria de los llamados contenidos audiovisuales está cambiando de un modo profundo, tanto en el terreno de las inversiones internacionales, para anticiparse al gran auge que las compañías tecnológicas están teniendo en la actual actividad económica mundial, como en las mismas profesiones del cine. El cine está siendo completamente redefinido. Ante este precipitado panorama, la enseñanza del cine en la universidad también debe, necesariamente, mirarse bajo otra luz.

\section{¿El cine tiene más que ver con la creación artística que con la comunicación?}

La enseñanza del cine es España se inició con la creación del Instituto de Investigaciones y Experiencias Cinematográficas (IIEC), creado en 1947 por el régimen, que impulsó un modelo formativo basado en la pericia y aprendizaje técnico de cara a crear a profesionales del medio que fueran capaces de engrosar la renaciente industria

\footnotetext{
${ }^{5}$ La formulación del concepto ontológico ha sido objeto de muchas interpretaciones en el terreno de la filosofía del cine, especialmente en el ámbito anglosajón a mediados de los 90. Se plantean cuatro teorías sobre la percepción de las imágenes en movimiento: de la ilusión (Illusion theories), de la transparencia Trransparency theory), de la imaginación (Imagined seen), del reconocimiento (Recognition thesis). Todas tienen algo en común: la teoría casual de la percepción. Las Teorías de la Ilusión de la percepción de la imagen, en boga en los setenta y primeros ochenta para explicar el poder de las imágenes para conformar la imaginación, plantean que vemos lo que una imagen muestra porque nos causa una experiencia visual que se corresponde con la experiencia visual que tenemos cuando vemos el objeto. Debemos haber sido engañados por la ilusión, una epistémica cognitiva. Las Teorías de la Transparencia asociadas a la tradición realista de la teoría del cine: Bazin, Kracauer y Cavell, plantean que las únicas propiedades que nos muestra la fotografía permiten ver realmente el objeto cuando vemos una película en movimiento. La Teoría de la Imaginación niega el hecho de que veamos lo que nos muestra la imagen en movimiento, más bien lo que la imagen muestra es lo que nosotros imaginamos que vemos. La Teoría del Reconocimiento, como las de la Imaginación, resuelve la paradoja de la percepción de las imágenes negando que, estrictamente hablando, nosotros vemos lo que la imagen muestra. Lo que vemos es una disposición de colores en una superficie plana con señales para nuestro proceso de reconocimiento de lo que la imagen es. Estas teorías están desarrolladas en Allen y Smith, 1997. En los últimos años, la irrupción del llamado Nuevo Realismo en la filosofía contemporánea impulsado por Maurizio Ferraris y seguido por otras figuras relevantes, como el filósofo alemán Markus Gabriel, ha supuesto un cuestionamiento de las posiciones posmodernas. Esta nueva corriente también se ha ocupado de la ontología y el cine (Ferraris y Terrone, 2018).
} 
cinematográfica franquista. Lo cierto es que la técnica del cine, tanto en el ámbito de la imagen como del sonido, encerraba una complejidad notable, lo que justificaba ese modelo, sin embargo, aunque tradicional y académico, estuvo también abierto a una cierta experimentación, en consonancia con otros cines nacionales europeos de la inmediata posguerra. A lo largo de su historia, este inicial espacio formativo tuvo distintas orientaciones pedagógicas y en él se formaron varias generaciones de grandes técnicos y cineastas ${ }^{6}$, hasta que en 1962 pasó a depender del Ministerio de Información y Turismo, cambiando su nombre por el de Escuela Oficial de Cine (EOC). Fue entonces cuando se produjo un cambio fundamental: El inicio de la adscripción del cine al territorio de la comunicación. En estos años comenzaba a perfilarse en Europa, especialmente en Francia (Cahiers du Cinéma, Trafic, etc.) un debate que situaba al cine como un lenguaje, expresión acuñada por André Bazin y cuya escena continuó posteriormente con el desarrollo de los estudios de semiología del cine. La EOC, tras su clausura en 1976, pasó a integrarse en la Facultad de Ciencias de la Información, perteneciente a la Universidad Complutense de Madrid. Esta adscripción de la enseñanza del cine al entorno de los estudios de comunicación tuvo dos consecuencias muy relevantes: por una parte, convirtió la enseñanza del cine en una titulación universitaria superior; por otra, la dotó de un perfil relacionado directamente con la televisión y los medios de comunicación. En los años siguientes, el espacio formativo del cine en la Educación Superior se asentó y se perfiló de un modo casi total en las distintas titulaciones de Comunicación Audiovisual presentes en las distintas universidades españolas. Así, a lo largo de los años 70 y primeros 80, la enseñanza del cine estuvo dominada por los estudios de comunicación, en diálogo con una formación técnica centrada en los soportes analógicos de la imagen vídeo. La irrupción de la sensibilidad posmoderna en España a mediados de los 80, con las primeras traducciones al castellano de la filosofía francesa, ampliaron y diversificaron los puntos de vista y esa teoría del cine tan enfocada en la comunicación fue abriéndose camino hacia otras contaminaciones. La categórica afirmación de que el cine no tiene nada que ver con la comunicación hecha por Deleuze, junto a sus influyentes ensayos específicos sobre cine, constituyeron un principio sobre el que construir un modelo de enseñanza del cine distinto al que se había ofrecido en España en las décadas anteriores, un modelo más abierto a otras complejidades, particularmente, al territorio del arte. Este enfoque del cine como un espacio más cercano a la experiencia de la creación artística planteó derivas y recorridos expresivos más distantes respecto a los conceptos netamente discursivos del cine y esto permitió a nuestro centro desarrollar un modelo de trabajo docente que integraba la enseñanza del cine dentro del horizonte de disciplinas del arte contemporáneo. Otras experiencias formativas como los talleres y masterclass llevados a cabo por cineastas con marcado perfil artístico como de Abbas Kiarostami, Peter Greenaway, David Lynch, Tim Burton o Gus van Sant, entre otros, cineastas formados en el ámbito de las Fine Arts, han constituido referencias importantes para situar nuestra concepción del cine y su enseñanza ${ }^{7}$ de un modo más firme en los últimos años. El territorio de la comunicación, sin embargo, ha continuado estando representado en nuestro centro con la presencia, desde sus inicios, del área de conocimiento de Comunicación Audiovisual dentro del Departamento de Arte. Pero el cine es una disciplina compleja y su presencia en el contexto de una titulación de Artes Visuales no ha sido sencilla, en la medida en que presenta problemas específicos y diferenciados en los terrenos conceptual e instrumental. Nuestra Facultad ha tenido que hacer un esfuerzo importante para desplegar una oferta formativa amplia y coherente, a la que hemos sumado la concurrencia de medios técnicos sustentados a través de proyectos de investigación, para la dotación de infraestructuras. Ha sido un proceso largo y complejo, llevado a cabo con el apoyo del grupo de investigación IDECA (Investigación y Desarrollo de Contenidos Audiovisuales), creado en 19998. Este colectivo ha desarrollado trece proyectos de investigación I+D e I+D+i a lo largo de los últimos veinte años, a través del los cuales ha realizado una aportación importante a la construcción de una base tecnológica sólida de cine profesional que ha situado a la Facultad

\footnotetext{
${ }^{6}$ Para ampliar esta información véase Ramos Arenas, 2016.

${ }^{7}$ También a partir de otros cineastas relacionados directamente con el mundo del arte, como Eisenstein, Buñuel, Antonioni, Kurosawa, Welles, Jarman, Schnabel, Salle, Ruscha, Van Sant o Almodóvar.

${ }^{8}$ Página web de IDECA: http://ideca.bellasartes.uclm.es/index.php/es/
} 
de Bellas Artes de Cuenca entre los centros mejor dotados en el contexto de las facultades de Bellas Artes en España. Además de este aspecto tecnológico, el grupo IDECA ha contribuido de un modo muy significativo en el espacio formativo, con experiencias de producción de contenidos que han estado relacionadas con el espacio docente,

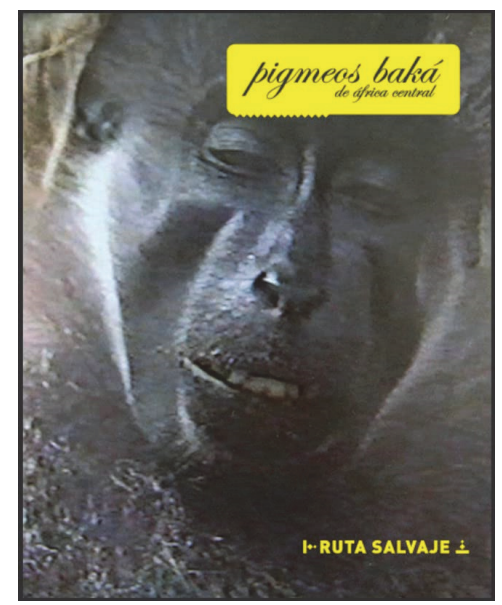

Figura 1. Carátula del documental Pigmeos Baká de África central, de la serie RUTA SALVAJE, producida con la colaboración del Grupo IDECA en 1999.

especialmente en posgrado, tanto en el terreno de la ficción como de la no ficción, en los que se han integrado también módulos de práctica en empresa. La serie documental RUTA SALVAIE, producida entre 1999 y 2001, desarrolló tres documentales de carácter etnográfico: Pigmeos Baká de África central, Mongoles del desierto de Gobi y Quechuas del Valle del Colca. En ellas se produjo un proceso de investigación antropológica y etnográfica previa, para sustentar un discurso conducente a dibujar el proceso de deterioro de la integración de estos pueblos en su medio en los últimos años. A esta serie siguieron otros documentales de investigación, como el dedicado al universo expresivo del cineasta Pedro Almodóvar titulado Inside Almodóvar (2003) que fue presentado en las jornadas de análisis sobre su obra celebradas en la Universidad de Harvard (Estados Unidos) en 2004.

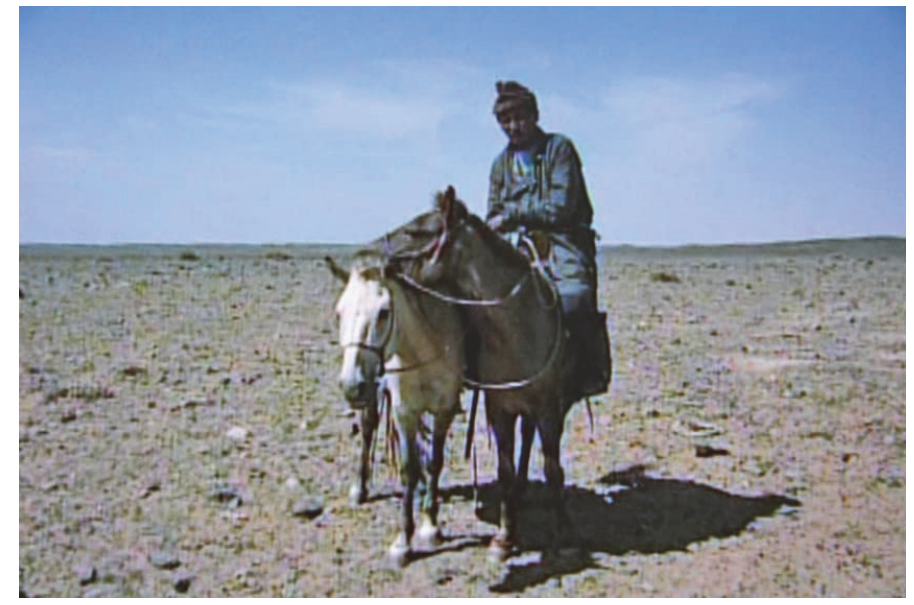

Figura 2. Fotograma del documental Mongoles del desierto de Gobi, de la serie RUTA SALVAJE, producido con la colaboración del Grupo IDECA, en 2000. 


\section{taphiya $\mathbf{4 8}$}

El proceso de investigación y producción de contenidos continuó con otro documental centrado en la Deportación, titulado Memoria del tiempo devastado (2006), en el que se desarrolló un dispositivo a partir del testimonio de uno de los últimos supervivientes del campo de exterminio de Mauthausen, para una relectura de la experiencia de la guerra. En los últimos años, el desarrollo de contenidos ha estado más centrado en el ámbito de la ficción y el grupo IDECA prepara, para los próximos años, nuevos proyectos de investigación centrados en diversos problemas sociales y

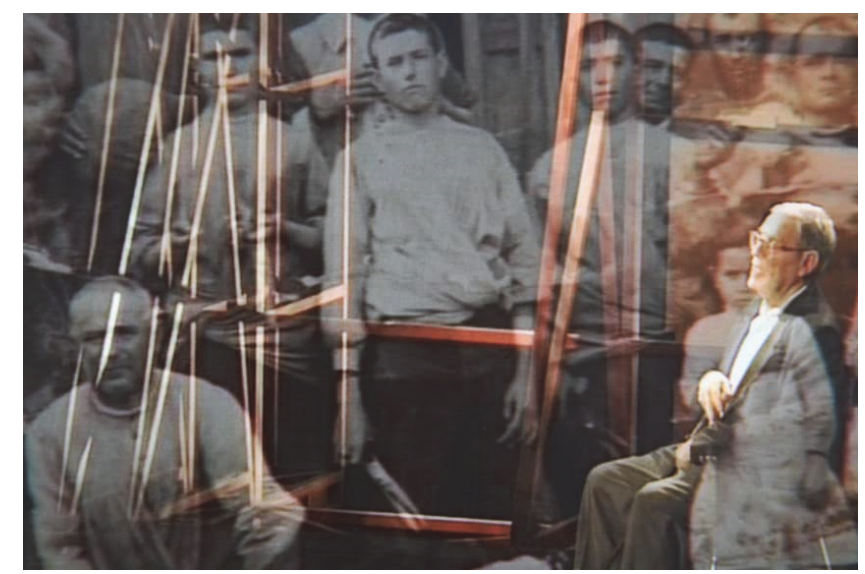

Figura 3. Fotograma del documental de investigación sobre la deportación titulado Memoria del tiempo devastado, producido por IDECA, en 2006.

culturales. Todos estos proyectos han tenido una huella formativa, con la colaboración a modo de prácticas de estudiantes de la Facultad. Si la docencia y la investigación son dos caras de la misma moneda y forman un binomio indisociable en la universidad, a través del cual se produce un enriquecimiento mutuo, la experiencia del Grupo IDECA ha cristalizado, además, en la puesta en marcha de espacios de análisis externos a la propia Facultad, como el conjunto de cursos sobre cine profesional llevados a acabo en la Universidad Internacional Menéndez Pelayo, en su sede de Cuenca, entre los años 2013 y 2019, en los que han participado un gran número de profesionales del cine español de gran relevancia en muy diversas áreas.

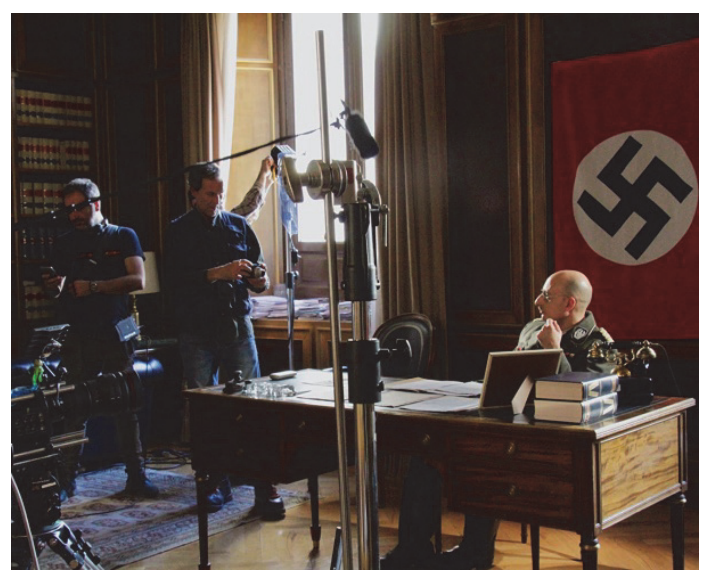

Figura 4. Momento del rodaje del cortometraje de investigación sobre España durante la Segunda Guerra Mundial titulado El emisario, producido en colaboración con el Grupo IDECA, en 2018. 


\section{taphiya $\mathbf{4 8}$}

\section{Investigación y capacitación profesional en posgrado}

Otro de los elementos que quisiéramos abordar y que figura entre nuestras preocupaciones presentes y futuras está relacionado con la capacitación profesional en posgrado. Mi tarea como director del Máster de Investigación en Prácticas Artísticas y Visuales de la Facultad de Bellas Artes de Cuenca en los últimos años ofrece una perspectiva sobre la que fundamentar la siguiente reflexión, que quisiera situar en el ámbito de las posibilidades de un modelo formativo mixto para los estudios de posgrado, capaz de incentivar la investigación y la capacitación profesional. El reto es abordarlo mediante la articulación de espacios de aproximación a modelos mixtos. El compromiso formativo con el estadio de capacitación profesional en el ámbito cinematográfico especializado de los egresados es muy importante para nuestro centro, de cara a ofrecer una mejor inserción laboral posterior. Las titulaciones generalistas presentes en la universidad española tienden a concentrar la especialización en Máster, pero sabemos cuáles son las limitaciones reales de la especialización en los módulos de investigación universitarios de un año que se presentan en la mayoría los Másteres. Las posibilidades reales son muy restringidas. Sin embargo, este es un aspecto muy demandado por los estudiantes, por tanto, se hace necesario investigar y diseñar nuevas estrategias conducentes a que, al menos en el ámbito de la enseñanza del cine, seamos capaces de proponer modelos que aseguren una iniciación a la investigación al tiempo que una capacitación profesional complementaria. En los debates de la Comisión Académica de Máster de nuestra Facultad estamos manejando dos ejes: uno tiene que ver con la estructuración de la enseñanza a través de talleres prácticos de capacitación técnico-investigadora de carácter inmersivo, que cuenten con el apoyo y asistencia de profesionales externos; el otro es la implementación de prácticas externas. En el modelo de Másteres vertebrados sobre talleres, que ya se lleva a cabo desde hace tiempo en el entorno anglosajón, se pueden inscribir los últimos trabajos llevados a cabo por el Grupo IDECA, con el desarrollo de contenidos de ficción como El emisario (2018), una película centrada en el papel de España durante los primeros años de la Segunda Guerra Mundial, o Dirección única (2019), que relata por primera vez desde el ámbito de la ficción, una hipótesis histórica sobre la muerte del filósofo alemán Walter Benjamín en Port Bou, en septiembre de 1940. Estos trabajos de investigación histórica se han realizado

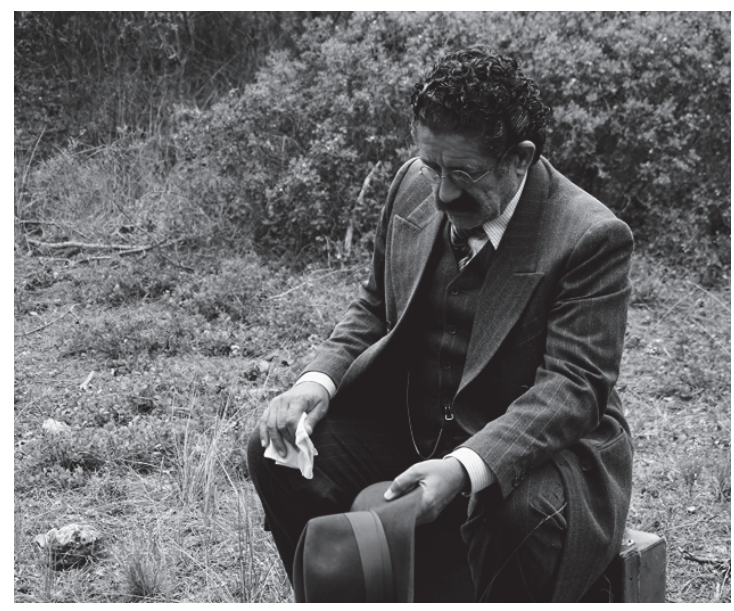

Figura 5. Momento del rodaje del mediometraje de investigación titulado Dirección única y centrado en la muerte del filósofo alemán Walter Benjamin, producido con la colaboración de IDECA, en 2019

a través de talleres formativos profesionales en el Máster de investigación. El otro eje que mencionábamos y que tiene que ver con el desarrollo de programas de prácticas en empresas, se halla sujeto a las tareas profesionales externas 


\section{taphiya $\mathbf{4 8}$}

ejercidas por los profesores que puedan ofrecer una transferencia, 0 bien a convenios con empresas del sector cultural. En ambos casos se exige un diseño específico, ya que es preciso tener en cuenta las limitaciones que impone el marco legal y el relevante soporte económico que necesitan estas actividades. Hay mucho trabajo por hacer. La enseñanza del cine es un territorio muy abierto en estos momentos dentro del marco de la Enseñanza Superior. En este reto formativo esperamos poder avanzar, para lograr que la formación cinematográfica de nuestra Facultad crezca y sea más competitiva que la que hemos sido capaces de ofrecer en los últimos treinta años. 


\section{taphiya $\mathbf{4 8}$}

\section{Bibliografía}

AlLEN, R. \& SMith, M. (EDS.) (1997). Film Theory and Philosophy. Oxford: Oxford University Press.

BazIN, A. (1990 [1975]). ¿Quées el cine?. Madrid: RIALP.

Bratu Hansen, M. (2012). Cinema and Experience. Siegfried Kracauer, Walter Benjamin and Theodor W. Adorno. Berkeley: University of California Press.

De LUCAS, G. (2014). Pedagogies de la creació. Comparat/ive Cinema, $n^{0} 5$.

http://www.ocec.eu/cinemacomparativecinema/index.php/ca/24-n-5-pedagogies-de-la-creacio/254-editorial-peda gogies-de-la-creacio

FerRaris, M. \& TerRone, E. (eds.) (2018). Cinema and Ontology. Milán-Udine: Mimesis.

LENNE, G. (1974). La muerte del cine (film/revolución). Barcelona.

MarTin, A. (2020). Arte correo cinematográfico. En C. Barrionuevo y M. Alderete (comp.): ¿Qué será del cine? Postales para el futuro. Mar del Plata: Festival Internacional de Cine de Mar del Plata.

Ramos Arenas, F. (2016). El instituto antes de Salamanca. Los primeros años del Instituto de Investigaciones y Experiencias Cinematográficas (1947-1955). Área abierta, vol. 16, n² 2, número monográfico "Miradas a la EOC", 13-26.

https://revistas.ucm.es/index.php/ARAB/article/view/52170 


\section{Resumen.}

La Facultad de Bellas Artes de Cuenca tiene un papel particular en la formación sobre cine en España. En sus programas de estudio y a lo largo de los últimos treinta años, se han incluido itinerarios y asignaturas específicas que han resultado muy significativas. Este artículo parte de unas consideraciones iniciales sobre el significado y la importancia de la enseñanza del cine en los diferentes niveles educativos y la necesidad de desarrollar estrategias para su mejor implementación en la Educación Superior. La última parte se presentan modelos históricos, perspectivas y algunos ejemplos metodológicos dados en la Facultad de Bellas Artes de Cuenca y relacionados con la experiencia investigadora.

Palabras clave. Cinematografía; Arte; Enseñanza; Investigación; Educación superior.

\section{Abstract.}

The Faculty of Fine Arts in Cuenca has a particular role in Cinema and Audiovisual formative matter in Spain. Some specific and significant audiovisual subjects that has been included and developed in its study programs along the last thirty years. This article starts with some initial considerations about the meaning and the importance of film teaching in the different education levels in Spain and the need to develop strategies for Superior Education. In the last part shows some historical models, perspectives and some examples of methodological approach given in the Faculty connected with the research experience.

Key-words. Cinema; Art; Teaching; Research; High education.

Ignacio Oliva Mompeán

Universidad de Castilla-La Mancha

ignacio.oliva@uclm.es 